Fecha de recepción: julio 2021

Fecha de aprobación: agosto 2021

Fecha publicación: septiembre 2021

\section{Mechanical design of the echinoid test and its biomimetic potentialities}

Valentina Perricone ${ }^{(1)}$, Francesco Marmo ${ }^{(2)}$, Carla Langella ${ }^{(3)}$, Gabriele Pontillo ${ }^{(4)}$, Luciano Rosati $^{(5)}$ y Maria Daniela Candia Carnevali ${ }^{(6)}$

\begin{abstract}
Echinoids, known as sea urchins, are invertebrates populating the seas since the late Ordovician. During their evolution, they underwent a relevant adaptive radiation leading to a variety of specialized forms and lifestyles. Most of the evolutionary success of echinoids is certainly due to the strategic employment of their endoskeleton, with particular reference to the coherent shell-structure of the test adapted to resist both biotic and abiotic stresses related to marine environments. This optimized structure, which minimizes both energy and materials employed, could also represent an ideal model for transferring functional bio-inspired solutions to building constructions and different industrial sectors. The present contribution intends to provide a short overview on the echinoid strategic morpho-functional adaptation of the test and its potential in the biomimetic field.
\end{abstract}

Keywords: Echinoids - Endoskeleton - Test - Mechanical design - Shell structures - Functional morphology - Biomimetics

[Abstracts in spanish and portuguese at page 109]

(1) Valentina Perricone is a naturalist and marine biologist; she achieved a bachelor's degree cum laude in "Natural Science" at the Federico II, University of Naples, Italy, and a master's degree cum laude in "Marine Biology" at the Alma Mater Studiorum, University of Bologna, Italy. She collaborated with the Smithsonian Tropical Research Institute of Panama - Collin's Lab, Bocas del Toro, Panama; the University of Florida - Invertebrate Paleontology, Gainesville, Florida, USA; the Zoological Station Anton Dohrn of Naples, Italy-department of Biology and Evolution of Marine Organisms (BEOM). Currently, she is an "Environment, Design and Innovation" $\mathrm{PhD}$ student and member of Hybrid Design Lab at University of Campania "Luigi Vanvitelli", Aversa (CE) where she also collaborates with Professor Carla Langella for "Bio-innovation design" and "Design for visualization of science" in the master course of "Design for Innovation". Her research topics regard marine ecology, functional morphology and biomimetic.

(2) Francesco Marmo graduated with honors in Civil Engineering in 2004 at the University of Naples Federico II, where he also obtained a PhD degree in 2008. Since 2013 he is assistant professor at the same University and teaches the MS course of Finite Element 
Analysis of Structures and the BS course of Continuum and Structural Mechanics. In 2018 he obtained the Italian Academic Qualification for the position of Full Professor of Continuum and Structural Mechanics. He actively participated to 10 founded research projects regarding the structural safety of heritage buildings and urban areas exposed to seismic risk. He is author of 38 articles on peer reviewed international journals receiving more than 450 citations with a $\mathrm{H}$-index of 15 and 55 papers presented at national and international conferences. His research regard assorted topics of computational mechanics applied to masonry and reinforced concrete structures, contact mechanics and inclusion problems. His research interests include: ULS analysis of RC cross sections; Non-linear analysis of framed and shear walled RC structures; Finite element formulations including mechanic and geometric nonlinearities; Elastic solutions for isotropic and transversely isotropic half-spaces; Potential theory; Form finding of mono-dimensional and bi-dimensional structural elements; Analysis of masonry arches and vaults.

(3) Carla Langella. Architect, Associate Professor of Industrial Design at the Department of Architecture and Industrial Design, University of Campania "Luigi Vanvitelli", where she teaches Bio-innovation Design and Design for Scientific Visualization in the master's degree Course Design for Innovation and Industrial Design Laboratory 3 in the Threeyear Degree Course of Design and Communication. In the field of experimental design research, she investigates the opportunities to build hybrid paths that involve the most advanced scientific contributions in the design project to bring contemporary science closer to people's lives. Since 2006 she founded and coordinates the Hybrid Design Lab (www. hybriddesignlab.org), the design laboratory dedicated to the mutual relations between design and science with particular attention to the experimentation of biomimicry in design and the integration of designers in the development processes of new materials to which the specific Designer in lab project is dedicated.hybriddesignlab@gmail.com

${ }^{(4)}$ Gabriele Pontillo is and Italian product designer. In 2015 he graduated in Design for Innovation at the University of Campania “Luigi Vanvitelli”. In 2019 he obtained a Doctoral Research Fellowship in Environment, Design and Innovation at the University of Campania “Luigi Vanvitelli". Main focus of his line of research are parametric design, medical design, and advanced manufacturing. The Ph.D. course with industrial characterization has allowed him to carry out and consolidate his research activity, as well as at his university, also at the Universidad Politécnica de Madrid (Spain), and a company from Campania, to design a system of innovative orthopedic devices. For the academic years 2017/18 and 2018/19, he was contract professor at the University of Campania "Luigi Vanvitelli" of the Digital Design course, part of the study plan of the first year of the Master's Degree in Design for Innovation. At the Department of Architecture and Industrial Design (DADI) of the same University, he collaborates with Prof. Carla Langella for Industrial Design III Laboratory, Bio-Innovation Design, and Design for Scientific Visualization courses.

(4) Luciano Rosati. Graduated summa cum laude from the University of Naples (UN) in Mechanical Engineering in July 1982. Graduated summa cum laude from UN in Civil Engineering in October 1984. PhD in Structural Engineering in October 1989. Research 
Fellow in Mechanics of Solids and Structures (MSS) (in Italian "Scienza delle Costruzioni") at the Faculty of Engineering (FE) of the UN since January 1990. Recipient of a NATO-CNR grant at the Department of Aeronautics of the Imperial College in London for studying large strain elastoplasticity under the supervision of prof. Mike Criesfield. Associate Professor of MSS at the FE of the UN since November 1998. Full Professor of MSS at the FE of the UN since November 2001. Member of the National Secretary of the Disciplinary Scientific Sector (SSD) ICAR/08-Scienza delle Costruzioni in the period 2004/2010. Coordinator of the Ph.D. Programme in Structural, Geotechnical and Seismic Risk of the at the FE of the UN Federico II in the period 2012/2020 President of the Area 08 of the National University Council (CUN) in the period 2015/2020. President of the Scientific Association SISCO (Italian Society of Scienza delle Costruzioni) since February 2021. Author of more than 100 papers published in peer-reviewed journal or proceedings of national and international conferences. Supervisor of ten Ph.D. dissertations and more than two-hundred BS or MS theses. Recipient of several national research grants.

(6) Maria Daniela Candia Carnevalli is Full Professor of Zoology at University of Milano, Department of Environmental Science and Policy and teacher of Animal Biology and Biomechanics. She has been Vice-Rector of Milano University; Head of the Department of Biology; President of the School of Biological Sciences; Coordinator of the Master Course on Biodiversity and Evolutionary Biology; National Coordinator of the Italian Schools of Biological Sciences. MDCC is author of more than 200 papers published in international peer reviewed journals and Editor of international books and journal issues. She was $\mathrm{Na}-$ tional winner of the Henry Ford Conservation Awards 1999 with the project: "Environmental stress, endocrine disrupters and regenerative phenomena in marine invertebrates". Her projects have been financed by EU; CARIPLO Foundation; Ministry of University and Scientific Research (MIUR); University of Milano (FIRST); National Council of Research (CNR). MDCC is an internationally recognized expert of echinoderm biology and is one of the world leaders in the study of "mutability" of the connective tissues and related phenomena such as auto-amputation (autotomy) and regeneration. These aspects have been study by integrated approaches including morphology, physiology and biomechanics also developing mathematical models. In these topics active and successful scientific international collaborations have been developed. 


\section{Introduction}

In the course of time, the unique constructional design of the echinoid endoskeleton has attracted the attention of researchers from diverse scientific areas due to its distinctive properties in terms of morphology, biomechanics, and materials (Perricone et al., 2020 and literature cited therein). Echinoids are highly adapted to different marine environments: the extant groups of regular and irregular sea urchins are widely distributed from the equator to the poles, from the bright shallow waters to the dark and cold deep-sea (Bovin et al., 2018). The evolutionary success of echinoids is certainly due to the massive strategic employment of their endoskeleton displaying numerous functional specializations. The echinoid endoskeleton consists of three main structural components: test, dental apparatus, and accessory appendages (Nebelsick et al., 2015; see Perricone et al., 2020 for a review). All skeletal parts are composed of high-magnesium calcite material; however, their microstructure displays a great potential encountering numerous different mechanical requirements according to a direct and evident structure-function relationship. This versatility has allowed the echinoid skeleton to fulfil different activities such as structural support, defence, feeding, locomotion, burrowing and cleaning. Although constrained by limits related to energy and available resources, many structures of echinoid skeleton are optimized in terms of functional performances and, consequently, can be used as role models for bio-inspired solutions in building constructions and various industrial sectors: from architecture and civil engineering to biomedical and new materials (Perricone et al., 2020). Attracted by the echinoid skeleton, Professor J. Knippers and co-workers from the Institute for Computational Design and the Institute of Building Structures and Structural Design, University of Stuttgart selected functional sea urchin characteristics translating them into different temporary wooden pavilions (2012 and 2015). In addition, they realized permanent constructions with computational design and digital fabrication: the Landesgartenschau Exhibition Hall (2014) and BUGA Wood Pavilion (2019) (Knippers \& Speck, 2012; Magna et al., 2013; Grun et al., 2016). An interesting example of bioinspired design of engineering products was instead realized by a group of engineers from the Jacobs School of Engineering, University of San Diego, California, in close collaboration with expert marine biologists. They considered Aristotle's lantern of the regular echinoid for the development of space exploration robots equipped with a gripping device useful for sediment collection (Frank et al., 2016). In addition, the lantern was also a source of inspiration for the development of a laparoscopic biomedical device (Jelinek et al., 2014). Likewise, the structure of echinoid spines inspired new materials (Moureaux et al., 2010; Presser et al., 2009; Tsafnat et al., 2012). The study carried out by Presser and co-workers on the Cidaroids Phyllacanthus imperialis and Heterocentrotus mammillatus demonstrated how the specific arrangement of the porous material, with different densities and architectures, is able to create extremely lightweight and resistant structures, i.e. ideal models for the realization of new ceramic materials in aluminium (Presser et al., 2011). Finally, Leigh et al. (2012) reproduced a responsive material with micro-actuators inspired by the pedicellariae, minute pincers present on the echinoid integument employed for cleaning and defence.

In this context, the present contribution presents the EchinoDesign project: a hybrid experimental research focused on the morphological and mechanical features of the echi- 
noid skeletal structure and aimed to acquire new biological insights, as well as, to identify adaptive solutions useful for biomimetic transfer applications in the Industry 4.0 Era.

\section{EchinoDesign: a trivalent hybrid approach to investigate the mechanical design of echinoids}

The EchinoDesign project was developed as an integrated experimental study on the echinoid skeletal structure carried out by an interdisciplinary group of biologists, engineers and designers of the University of Campania "Luigi Vanvitelli", the University of Naples Federico II, and the University of Milan. Through the combination of methods and tools of biology, engineering and design, the EchinoDesign aimed to:

1. Study the morphological-functional adaptations of the skeletal system of the regular echinoid Paracentrotus lividus;

2. Identify biological rules and principles underlying the different structural solutions; 3. Select and analyse individual details that can be reinterpreted (according to the analogies with design problems) and transferred as intelligent solutions to building construction and industrial design products leading to progress and advantages.

EchinoDesign involved a trivalent hybrid approach, based on the synergistic cooperation between biologists, engineers and designers, in which each competence continuously interacts with the others leading to a unique and creative process. The results of this hybridization can be identified in new biological species-specific knowledge, abstractable principles and technical innovation. The process can be summarized in six key phases:

(1) Identification of biological models on the basis of analogical function and problem solving related to the final application;

(2) Deconstruction survey, where the organism is subjected to a particular "reverse engineering" process and is schematized into functional components at different dimensional scales (shapes, structures, patterns, textures, etc.) in order to reveal its design and architecture;

(3) Direct investigation to increase the species-specific organism comprehension;

(4) Identification of functional biological principles and abstraction into design principles;

(5) Contextualization and transfer of the abstracted models into the design of new bioinspired concepts;

(6) Development of the bioinspired design artefacts, optimization, prototyping, tests and validations.

Following the hybrid process, the sea urchin P. lividus was chosen as a biological model and investigated in depth. After an initial description, the endoskeleton of the P. lividus was schematized into different functional components at different dimensional scales and characterized based on current knowledge and accurate visual surveys at a macro and 
microscale (deconstruction survey). This survey highlighted different details that were categorized and described. Following the hybrid process, among these functional skeletal components, the test was taken into consideration for an in-depth study in order to acquire novel understandings regarding mechanical design and adaptive strategies. The support and protection of visceral organs is the primary role of the echinoid test; it must likewise robust enough to withstand forces acting on it, but also sufficiently flexible to allow growth and movement. Consequently, this skeletal system can be investigated as an engineering structure with possible applications of biomechanic notions. Based on these assumptions, section 2.1 presents in-depth studies of the P. lividus test subjected to a hybrid analysis using stereomicroscopy, scanning electron microscopy, photogrammetry, 3D modelling and Finite Element Analysis. Once identified shapes and structures corresponding to adaptive strategies and functional principles, they were abstracted and transferred into building construction and industrial design products. As a result, P. liv$i d u s$ became a guide and model for the development of different bio-inspired concepts.

\subsection{Regular Echinoid Test: a hybrid investigation}

The echinoid test was identified as a biological model and based on both functional analogy and problem solving was related to the final application. The echinoid test is described as a 3D structure resulting from the rotation of an arch, i.e. a dome or echinodome, characterized by a thin shell and double-curved architecture (Telford, 1985). This configuration leads to a mechanical behaviour following the membrane theory: in-plane membrane stress and reduced bending and out-of-plane shear stress. The echinoid test is also a sophisticated multi-element shell system consisting of several skeletal plates joined by sutures. These sutures can be characterized by the presence of interdigitating articular surfaces (finger joints) suitably bound together by short collagenous ligaments possibly exhibiting modular stiffness (Mancosu \& Nebelsik, 2020). In a design perspective, analogous functions to those of the echinoid test are: external protection, containment and mechanical support. The shape of the test and its interlocking plates can protect the organism in harsh underwater environments. The functional characteristics of the test are particularly useful in the designing of stable, resistant, flexible, and adaptable structures to be used in various building construction and industrial sectors e.g., packaging, external supports or protections.

\subsubsection{Deconstruction survey}

In this survey, specimens of Paracentrotus lividus were analysed at a macro and microscale using a stereomicroscope and scanning electron microscope and subsequently schematized into different functional components.

Paracentrotus lividus is macroscopically characterized by a flattened circular test with a diameter not superior to 6-7,5 cm (Bonnet, 1925; Boudouresque et al., 1989; Boudouresque \& Verlaque, 2001; Lozano et al., 1995). Although the popular name is 'purple sea urchin', its colour varies: black-purple, purple, red-brown, dark brown, yellow-brown, light brown, 
or olive green. The test consists of a regular series of skeletal plates forming an evident pentaradially symmetrical structure. The plates are organized in four pentameric systems:

1. Coronal system, composed of meridian areas divided into 5 interambulacral and 5 ambulacral. The first having articulated spines and pedicellariae, the latter having articulated spines and 5-6 pairs of pores for the tube feet passage;

2. Apical system consisting of 5 genital plates (of which one represents the madreporite), alternating with 5 smaller ocular plates;

3. Periproctal system, constituted by plates arranged in an irregular circle surrounding the flexible membrane presenting the anus opening;

4. Peristomial system, consisting of numerous plates protecting the wide flexible membrane surrounding the mouth (Boudouresque \& Verlaque, 2001; Brusca \& Brusca, 2003) (See Figure 1).

The first three well observable in an aboral view and the fourth in an oral view. Due to the regular alignment, each ambulacral zone displays an overall central suture line (perradial suture) between the two parallel series of plates; each interambulacral zone has an interradial suture at midline; in addition, the joints between inter-ambulacral and ambulacral zones are defined by adambulacral suture lines (Mancosu \& Nebelsick, 2020). Since all plates bear movable spines, the outer surface of the ambulacral and interambulacral plate displays rounded tubercles on which primary or secondary spines are suitably articulated by ball-and-socket joints.

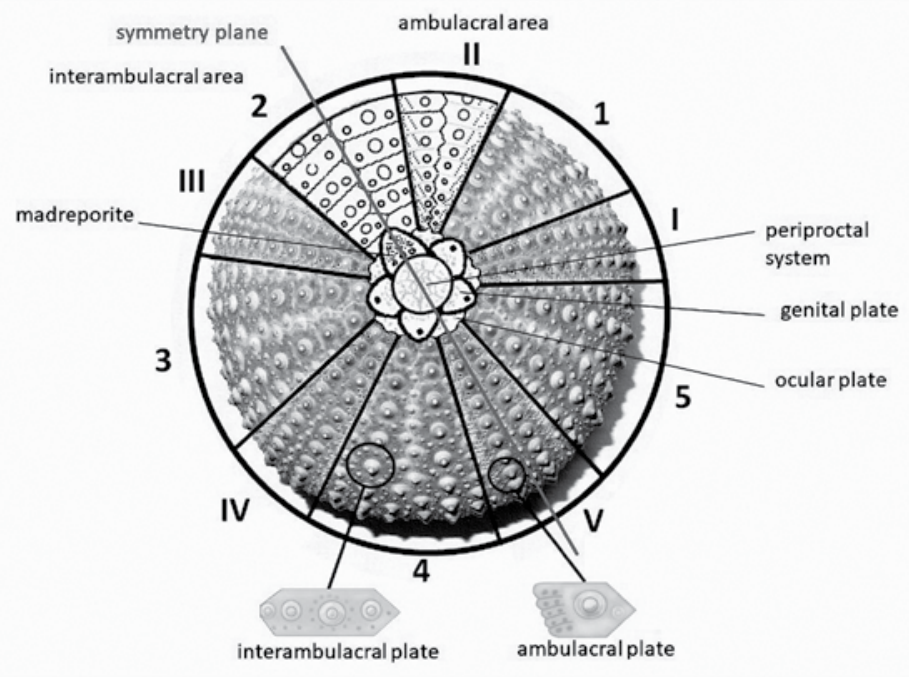

Figure 1. Aboral view of Paracentrotus lividus test illustrating the radially symmetrical pattern. The following features can be distinguished: coronal system composed by skeletal plates arranged in five ambulacral (1-5) and five interambulacral (I-V) areas; apical system, consisting in 5 genital plates (one madreporite), alternating with 5 smaller ocular plates; periproctal system consisting of plates arranged in an irregular circle surrounding the anus. 
In the microscale, $P$. lividus skeletal plates consist of a peculiar light-weight microstructure, called stereom, organized according to a porous three-dimensional (3D) lattice-like meshwork, whose rod-like trabeculae measures about $8 \mu \mathrm{m}$ in length. The stereom is highly variable in density and architecture and is filled with cells and organic material called stroma, which comprises cells, collagen fibres and extracellular matrix (ECM). This architecture is extremely complex, largely varying not only from species to species, but also within the different test plates. It consists of different basic types (e.g. imperforate, galleried, labyrinthic, fascicular, laminar) associated in a variety of different combinations, creating species-specific 3D structural patterns that are clearly distinguishable when the plates are sectioned. The skeletal material tends to increase in density in different regions subjected to high stresses, e.g. tubercles and basal zone, and to be specialized in a regularly oriented porous arrangement (galleried stereom) in zones more subjected to directional forces, i.e. sutural zones. The suture area exhibits specialized and complex structural adaptations related to both stereom and stroma, including:

1. Skeletal complementary protrusions (finger-joints) interlocking adjacent plates (Ellers et al. 1998; Gun et al, 2016) that hinder local disarticulations and ensure stability of the test; 2. Presence of short and strong articular ligaments, consisting of parallel bundles of densely packed collagen fibrils, which presumably behave as a rigid or semi-pliant material according to functional needs (Mutable Collagenous Tissue-MCT: Wilkie et al., 2005, for a review).

\subsubsection{Functional performances and transferable properties}

The previous survey, together with knowledge provided by literature, highlighted different functional features which contribute to the stability and resistance of the echinoid test structure. Accordingly, the echinoid test can be schematized into the following different functional components (See Figures $2 A, B, C, D, E, F, G, H$, and I):

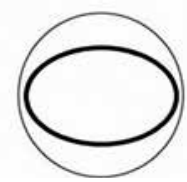

$2 \mathrm{~A}$

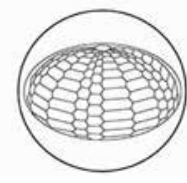

2B

Figure 2A. Shape. The test is oblate shaped assuming the form of a flattened sphere and resembling an architectural dome (Telford, 1985). During growth, it acquires this shape presumably resulting in a stable geometry funicular to self-weight and coelomic pressure (Ellers \& Telford, 1992). The internal pressure balances the surrounding water pressure and was also found to fluctuate rhythmically of about -8 Pa (Ellers \& Telford, 1992) providing the test with compressive compactness. Even though the ideal form of the test should be that of a sphere, downward forces from calcite underwater weight and tube feet pull are most probably the cause of polar flattening (Ellers \& Telford, 1992; Philippi \& Nachtigall, 1996). Figure 2B. Subdivision into plates. The echinoid test is a modular structure divided into plates, each with a different shape and function, providing organisms with great flexibility during growth, greater structural resistance, and damage limitation (Telford, 1985; Ellers et al, 1998). Piercing loads, such as those caused by predator actions, are transferred through all skeletal plates rather than affecting one. For a better comprehension, two 


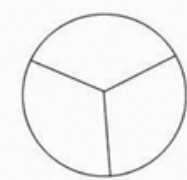

2C

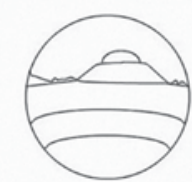

2D

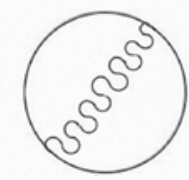

2E

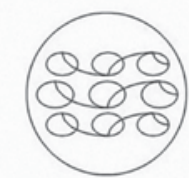

2F

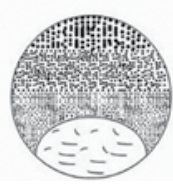

2G

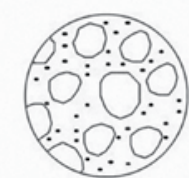

$2 \mathrm{H}$

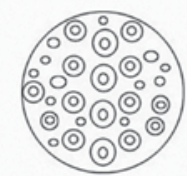

$2 I$

types of hollow glass balls can be used as an example: one ball consisting of a single piece and another of many fitted together. Piercing the single piece ball will result in cracking and in its probable destruction. Conversely, piercing the multiple pieced ball will cause the cracking of only a single or few pieces, but the overall ball will remain intact ${ }^{1}$. Hence, echinoids prevent test cracking and breaking by distributing impact forces throughout their different test plates (Vogel, 2013). Figure 2C. Trivalent vertex principle. In the echinoid test, the plates are arranged following the trivalent vertex principle; in which three plates meet in one point (Wester 1984; 1990; 2002). This is a stable configuration and a structural pattern characteristic for pure plate structures, the echinoid test being an outstanding example. As described by Wester (1984) a plate structure consists of plates and lines of support. The forces generated between the plates are only shear forces. Considering a horizontal plate in a three-dimensional space: a plate hinged along one or two lines of support is movable for forces not directed through the intersection points; conversely, a plate hinged along three lines of support is not movable by any direction of forces, resulting in a stabilized plate. Figure 2D. Plate curvature. The plates are visibly curved following the flattened sphere of the test (Telford, 1985). Curved hinges avoid rotation mechanisms even with only one line of support per plate, preventing bending action transfer. Figure 2E. Finger-joints. Knob-like spherical protrusions allowing interlocking between the complementary plates preventing shearing movements (Wester, 2002; Mancosu \& Nebelsik, 2020). Under loading, the small plates of the sea urchin test interlock creating a stronger shell structure. Figure 2F. Collagen fibres. Anelastic flexible fibres joining the plates dissipate normal, shear and flexural forces, increasing the stability of the structure (Ellers et al., 1998). The collagen fibres may have an important role in keeping the whole structure assembled by pre-compressing the joints, as well as, in sustaining and transmitting stresses particularly during the repair period from eventual breakage of one or more plates (Wester, 2002). Additionally, unlike other shells, tests are growing structures composed by articulated hard elements. Thus, collagen-swathed sutures permit growth and local deformation reducing impact loading and therefore offsetting the eventual hazards of a thin shell (Telford 1985). Figure 2G. Material differentiation. The stereom microstructure is highly variable in density and architecture and is filled with cells and organic material (stroma). This architecture is extremely complex, largely varying not only from species to species, but also within the individual echinoid test plates. The microstructure is characterized by variable oriented trabeculae of different basic types (e.g., imperforate, galleried, labyrinthic, fascicular, laminar) associated in very different combinations, creating species-specific 3D structural patterns (Smith, 1980a). The differentiation depends on three main factors: associated soft tissues, mechanical needs and growth rate (Smith, 1980a). It optimizes the use of material, whereas the structural specialization increases the mechanical resistance, ensuring lightness and a high level of robustness (Grun \&Nebelsick, 2018; Nichols \& Currey, 1968). Figure 2H. Functional porosity. Porosity is highly variable within the skeleton according to local functional needs. In a mechanical perspective, internal porosity ensures lightness and saves material without compromising the overall skeletal resistance (Grun \& Nebelsick, 2018; Nichols \& Currey, 1968), as well as reduces cracking eventuality (Vogel, 2013). Furthermore, open pores provide an attachment site for muscles and ligaments, as well as permeability and connections to the external environment. Examples for the latter function are the madreporite, a modified highly porous plate used to filter and balance the water vascular system, and gonopores, passageways for eggs and sperm release (Brusca \& Brusca, 2003). Figure 2I. Ornamentation. The plates are characterized by a series of species-specific tubercles and fine-relief ornaments. Tubercles serve as multiple articulation surfaces for spines (ball and socket joint) and pedicellariae allowing these appendages to exploit the wide range of movements related to their diverse functional roles (Smith, 1980b). The plate surface ornamentation can indicate habitats and growth patterns of extant and fossil echinoids (Oldfield, 1976). 


\subsubsection{Echinoid test investigation}

The deconstruction survey revealed design and architecture of the echinoid test; it also permits to identify the main gaps in knowledge on its morphology and structure. In particular, in answer to the question on how sutures influence the mechanical behaviour of the overall test a direct investigation was elaborated. Using different mechanical experiments (crushing, three-point bending and tensile tests), Ellers and co-workers (1998) demonstrated how collagenous sutural ligaments improve the structural strengthening of sea urchin skeletons. However, they did not consider the bending behaviour of sutures and how this influences the distribution of bending actions within the entire shell of the test. Thus, to better understand the role played by the flexible connection between the rigid hexagonal plates, a Finite Element (FE) analysis of the test of P. lividus was performed. The geometry of the test was obtained by means of a photogrammetric survey, which was regularized by employing a parametrized description and then partitioned into plates and sutures in order to separate the regions having different structural behaviour. Starting from this unique geometry, two different models were obtained: a monolithic and a segmented model. They differentiate for the way sutures are modelled. In particular, the monolithic model was obtained by assigning the same material properties for both plates and sutures, whereas the segmented model is characterized by reduced flexural stiffness of the elements corresponding to collagenous sutures (See Figure 3).

Several analyses were conducted on both monolithic and segmented models considering different loading conditions corresponding to normal and tangential loads applied to a test portion. Figure 3 shows the contour-plots of the bending stresses generated by a normal load applied to the circular portion of the structure. As clearly visible, the segmented model exhibits a significant reduction of bending actions compared to the monolithic one.

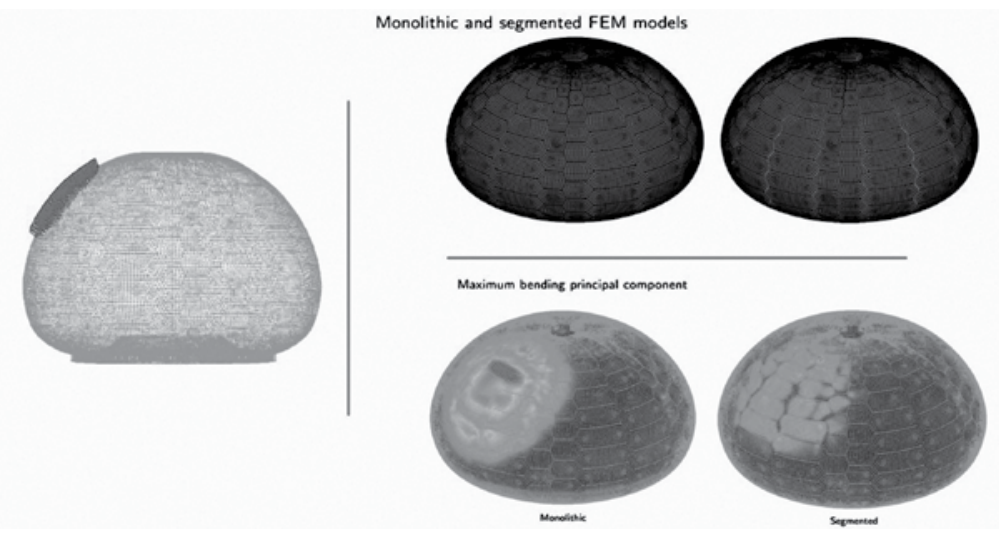

Figure 3. Paracentrotus lividus test. Loading condition and bending stresses computed for monolithic and segmented shells. 


\subsubsection{Echinoid inspired applications}

The analyses presented in the previous section provided important knowledge about the mechanical design of the test and the biological principles behind it: the global mechanisms of the test are avoided by the trivalent vertex arrangement, curved edges and the interlocking among plates; whereas, the flexible sutures were identified as a functional biological principle in reducing bending stress. This knowledge was abstracted as bioinspired solutions for the designing of new types of shell structure composed of rigid modules with flexible joints and design products.

\subsubsection{Shell structures for building constructions}

Project name: Bioinspired shell structures

Research team:

Francesco Marmo, Deptartment of Structures for Engineering and Architecture, University of Naples Federico II, Napoli, Italy

Luciano Rosati, Deptartment of Structures for Engineering and Architecture, University of Naples Federico II, Napoli, Italy

Valentina Perricone, Department of Engineering, University of Campania Luigi Vanvitelli, Aversa, Italy

Carla Langella, Department of Architecture and Industrial Design, University of Campania Luigi Vanvitelli, Aversa, Italy

Gabriele Pontillo, Department of Engineering, University of Campania Luigi Vanvitelli, Aversa, Italy

The echinoid strategy was abstracted and applied to design multiple closed and opened variable shaped shells. These are characterized by a discontinuous structure composed by rigid hexagonal modules with curved edges and flexible joints arranged according to the trivalent vertex principle. In the following figure, an open plexiglass shell conceived as a space-divider for exhibition and fair events in the after-COVID-19 scenario is shown as an example.

The designed shell was analysed considering gravity, wind, anthropic and seismic actions. Figure 4 illustrates the comparison of the bending stresses generated by a gravity load between monolithic and segmented models. From this comparison, it is clear that the presence of flexible joints significantly reduces the maximum value of the bending stresses within the shell structure. 


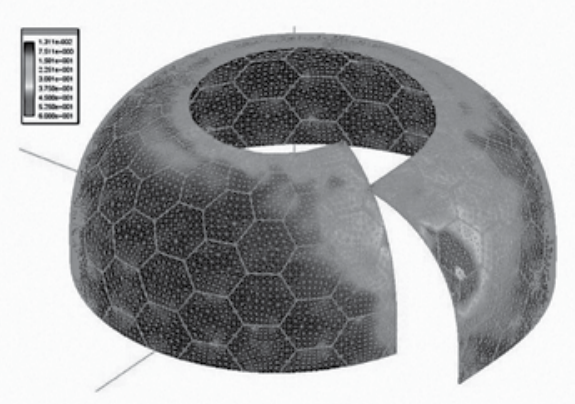

Monolithic model

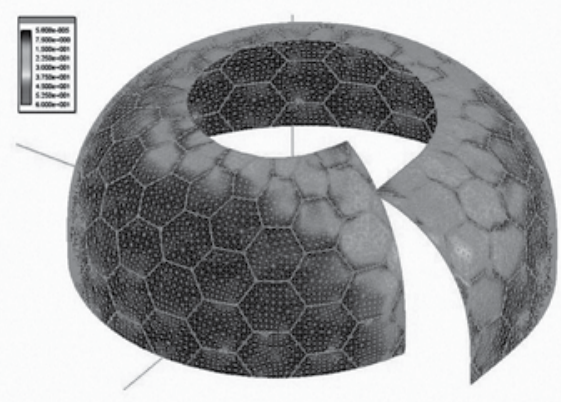

Segmented model

Figure 4. Bending stresses in open plexiglass shells: monolithic (left) vs. segmented (right) generated by gravity load.

\subsubsection{Design products}

The identified adaptive solutions of the test, as a modular system guaranteeing high integrity and structural stability in different stress conditions, were transferred into the design of back-braces for scoliosis treatment (under patent request), sportive protective gear and vaccine packaging. Shapes and structures of the biological model were abstracted and applied, according to principles of functional analogy, and reproduced in parametric 3D computer aided design (CAD) models responding to specific innovation needs requested by users.

\subsection{Sportive helmet}

\section{Research team:}

Carla Langella, Department of Architecture and Industrial Design, University of Campania Luigi Vanvitelli, Aversa, Italy

Valentina Perricone, Department of Engineering, University of Campania Luigi Vanvitelli, Aversa, Italy

Gabriele Pontillo, Department of Engineering, University of Campania Luigi Vanvitelli, Aversa, Italy

Design: Giorgio Carotenuto, Vincenzo Giorgione, Natalia Janquin, Alessia Masiello, Mario Matarazzo, Terry Celentano, University of Campania Luigi Vanvitelli, Aversa, Italy 
In this project, different echinoid strategies were abstracted and applied using 3D printing to design and realize new lightweight and resistant sportive helmet destined for example to bike, rollerblades, skates, skateboards, as well as electrically powered scooters.

\section{Design problem}

Foam and shell are the principal components for helmets. Foam absorbs most impact energies, whereas the shell provides mechanical resistance and head protection distributing impact loads on a wider foam area increasing energy absorption capacity. The use of additive manufacturing in the realization of helmet has many advantages, such as freedom of form, customization, and cost reduction; however, the use of this manufacture technique is generally limited due to the insufficient strength of the resulting products. Considering that helmets should be highly resistant to prevent head injuries, a weak point is not acceptable.

\section{Design challenge}

Increase the shell structure resistance circumventing the 3D printing limitation.

\section{Bioinspired solution}

The analysis of the echinoid test, together with literature regarding other multiple-plate skeleton performances (e.g., turtle and human skull), led to the abstraction of different functional principles in the designing of new shell structures for 3D printable helmets. The following details and principles were abstracted:

1. Modular shell system for impact protection;

2. Hexagonal modules as optimized surface tessellation to form a continuous modular grid;

3. Flexible edge material able to dissipate stress;

4. Module arrangement following the trivalent vertex principal to avoid global mechanisms;

5. Curved modules to avoid relative rotation between plates.

\section{Bioinspired product description}

The echinoid-inspired helmet is characterized by a modular structure divided into perforated and curved hexagonal modules designed to ensure breathability, lightness, and material reduction (See Figure 5). The modules follow the trivalent vertex arrangement and are particularly shaped with geometrically angled edges filled with flexible silicon materials intended to dissipate stress, guaranteeing a high structural performance and function of the protectors easily realized using 3D printing. Helmets are created in $3 \mathrm{D}$ printing using a variation of materials between hexagonal modules and edges; the first characterized by $20 \%$ flexibility and $80 \%$ stiffness, while the second by $80 \%$ flexibility and $20 \%$ stiffness. The use of $3 \mathrm{D}$ printing accelerates the product development process and is usually cheaper than other fabrication techniques. Another major advantage is the possibility of creating complex customizable structures based on the user size and preferences. 3D printing has been in use since $1986^{2}$ as a prototyping technique; however, 

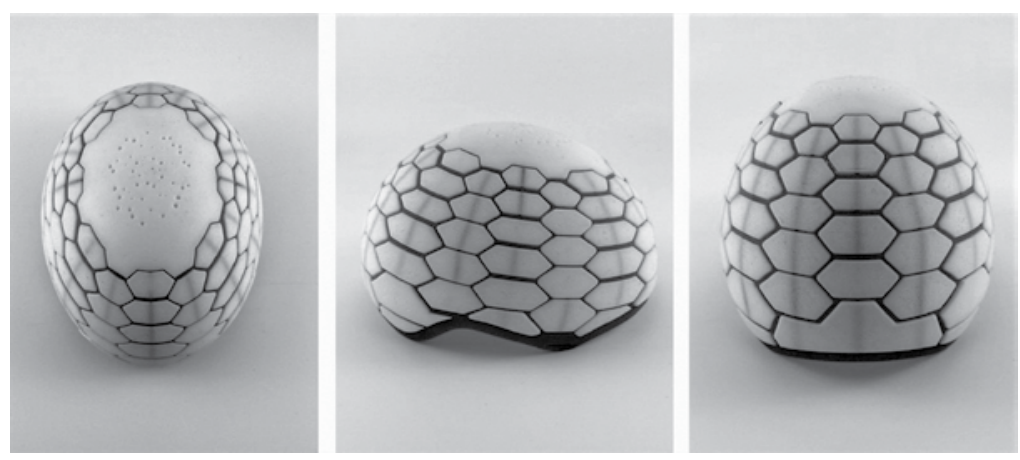

Figure 5. Echinoid-inspired sportive helmet fabricated using 3D printing varying materials, which are respectively characterized by a flexibility from $20 \%$ to $80 \%$ and stiffness from $80 \%$ to $20 \%$.

it is presently possible to use additive manufacturing of finished and high-performance products through increase in their structural strength. Moreover, presently, 3D printing material quality is continuously improving, allowing production of parts similar to those of traditional manufacture.

\subsection{Asha: vaccine packaging}

Project name: Asha vaccine packaging

\section{Research team:}

Nikhil Shamrao Autade, Industrial designer, IDC, Indian Institute of Technology

Valentina Perricone, Department of Engineering, University of Campania Luigi Vanvitelli, Aversa, Italy

Pallavi Gadhave, Pharmacologist, Nashik District Maratha Vidya Prasarak.

Pooja Gaikwad, IT Engineer, Sanjivani Rural Education Society

Vishal Gaikwad, Sr. Software Developer, Modern Collage Shivajinagar Pune

This project regards the development of a bioinspired packaging for vaccines resistant to impacts and maintains a temperature monitored by mobile technology.

\section{Design Problem}

In order to maintain their efficacy, vaccines usually need a "cold chain" within a specific temperature range (normally between $+2^{\circ} \mathrm{C}$ and $+8^{\circ} \mathrm{C}$ ) from manufacturing to use.

In regions where continuous power supply is not ensured, the "cold chain" can be difficult to maintain. In remote places like the Himalayas (Nepal) and Indian villages, refriger- 
ation services cannot be maintained. The numerous lives lost due to, i.e. poliomyelitis and SARS-CoV-2, have highlighted the worldwide importance and necessity for vaccines. Nevertheless, sensitive to heat, $25 \%$ of vaccines are lost due to the lack of a cold chain. In some cases, although having lost their efficacy, vaccines have been however administered due to the lack of quality control and logistics management as reported by The Times of India $(2016)^{3}$. This poses a major challenge to world governments as well as public health agencies working to ameliorate immunization coverage.

Currently, ice packs are used to refrigerate cold boxes to maintain controlled temperature. However, since the temperature is not constant, the effectiveness of the vaccine is not ensured.

\section{Design challenge}

Create new packaging with an integrated cold chain system and external protection with the aim to deliver vaccines integrate, safely and continuously monitored.

\section{Bioinspired solution}

Multiple adaptive solutions of the test were transferred into the design project, namely: modular structure, material differentiation and hydraulic system. Structures and systems of the biological models were emulated and applied, according to functional analogy principles and reproduced in parametric 3D computer aided designs (CAD) models responding to specific innovations. As a result, the echinoid strategies led to the development of new functionalities, namely:

1. Structural resistance, obtained by a discontinuous structure consisting of hexagonal modules connected by flexible material (material differentiation);

2. Dynamicity, ensured by reversible modules allowing the removal, addition and / or replacement of individual modules containing vaccines;

3. Temperature regulation, ensured by circulating fluid cooled by an autonomous controlling system.

\section{Bioinspired product description}

Asha consists of a discontinuous structure characterized by multiple layers of rigid, soft, and fluid materials with hexagonal modules connected by flexible material (See Figure 6). The middle layer consists of flexible material containing a refrigerated fluid, which surrounds the hexagons and represents the flexible material part. Temperature regulation is ensured by the circulating fluid cooled by an autonomous controlling system composed by a controller and sensors. This system refrigerates the fluid keeping the vaccine within the necessary temperature range. The packaging product is created and realized using digital manufacturing. Accordingly, customization for different needs and preferences, as well as further product development are provided by an elevated versatility of shapes, geometries, colours, and systems obtainable by parametric designs and digital manufacturing. ASHA is fabricated by additive manufacturing using dedicated medical antibacterial materials consisting of copper nanoparticles that counteract the adhesion and proliferation of bacterial biofilm on the surface of an object. Industries, such as $3 D$ copper, developed 


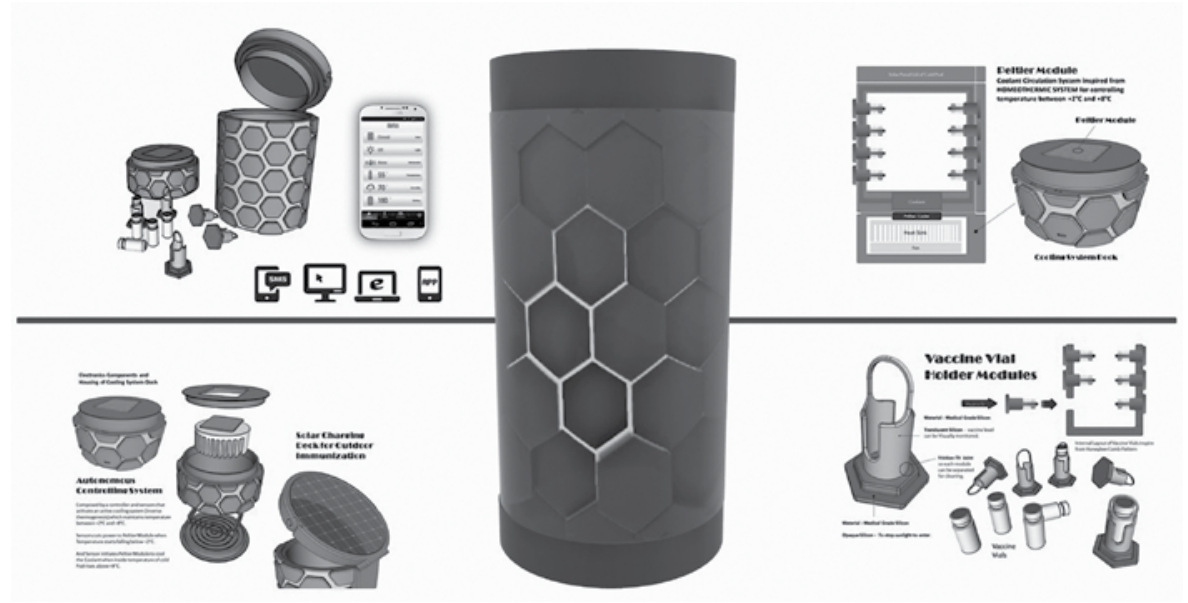

Figure 6. Asha. Packaging design components submitted to the Biomimicry Global Design Challenge 2019.

these materials managing to use copper nanoparticles within polymers such as PLA and TPU adding antibacterial properties to the filaments.

In a future perspective, ASHA aims to become a new start-up of bioinspired packaging lines for vaccines and biomedical sectors. Therefore, it can be considered a dynamic evolving product able to address in the future different emerging needs based on the biomimicry process. Consequently, ASHA intends to develop a scalable business model based on:

- Continuous research activities intended to create a dynamic bioinspired library. New solutions and products can be developed and updated due to constant research.

- A repeatable and expandable business model: a functional business model will be nationally and internationally applied and replicated; commissions taken up via web will overcome territorial limits.

- Possibility of future investments and sponsorships: investments in expansion of new expertise and staff members will increase the efficiency of the product line and commissions, while acquisition of new instruments will offer novel technical features and additional transfer and design services.

\section{Notes}

1. https://asknature.org/strategy/sea-urchin-shell-effectively-prevents-cracking-andbreaking/ 
2. Charles W. Hull (1986) Apparatus for production of three-dimensional objects by stereolithography. Patent n. US4575330B1.

3. https://timesofindia.indiatimes.com/india/25-of-vaccines-go-waste-due-to-lack-ofcold-chain/articleshow/52999274.cms

\section{References}

Boivin, S., Saucède, T., Laffont, R., Steimetz, E., Neige, P. (2018) Diversification rates indicate an early role of adaptive radiations at the origin of modern echinoid fauna. PLoS ONE. 13.

Bonnet, A. (1925). Documents pour servir all'étude des variations chez les echinides. Bulletin de I'Institut Oceanographique de Monaco, 462, 1-28.

Boudouresque, C. F. \& Verlaque, M. (2001). Ecology of Paracentrotus lividus. Developments in aquaculture and fisheries science, 32, 177-216.

Boudouresque, C. F.; Verlaque, M.; Azzolina, J. F.; Meinesz, A.; Nedelec, H. y Rico, V. (1989). Evolution des populations de Paracentrotus lividus et d'Arbacia lixula (Echinoidea) le long d' un transect permanent a Galeria (Corse). Travaux scientifiques du Parc naturel régional et des réserves naturelles de Corse, 22, 65-82.

Brusca, R. C. \& Brusca, G. J. (2003). Invertebrates (No. QL 362. B78 2003). Basingstoke.

Ellers, O. \& Telford, M. (1992). Causes and consequences of fluctuating coelomic pressure in sea urchins. The Biological Bulletin, 182(3), 424-434.

Ellers, O., Johnson, A.S., Moberg, P.E. (1998) Structural strengthening of urchin skeletons by collagenous sutural ligaments. The Biological Bulletin, 195(2), 136-144.

Frank, M. B.; Naleway, S. E.; Wirth, T. S.; Jung, J. Y.; Cheung, C. L.; Loera, F. B.; Medina, S.; Sato, K. N.; Taylor, J. R. \& McKittrick, J. (2016). A protocol for bioinspired design: A ground sampler based on sea urchin jaws. Journal of Visualized Experiments: JoVE, (110).

Grun, T. B. \& Nebelsick, J.H. (2018). Structural design of the minute clypeasteroid echinoid Echinocyamus pusillus. Royal Society Open Science, 5(5), 171323.

Grun, T. B.; Dehkordi, L. K. F.; Schwinn, T.; Sonntag, D.; von Scheven, M.; Bischoff, M., ... \& Nebelsick, J. H. (2016). The skeleton of the sand dollar as a biological role model for segmented shells in building construction: a research review. Biomimetic Research for Architecture and Building Construction, 217-242.

Jelínek, F.; Smit, G. \& Breedveld, P. (2014). Bioinspired spring-loaded biopsy harvesterexperimental prototype design and feasibility tests. Journal of Medical Devices, $8(1)$.

Knippers, J. \& Speck, T. (2012). Design and construction principles in nature and architecture. Bioinspiration \& biomimetics, 7(1), 015002.

Leigh, S. J.; Bowen, J.; Purssell, C. P.; Covington, J. A.; Billson, D. R. \& Hutchins, D. A. (2012). Rapid manufacture of monolithic micro-actuated forceps inspired by echinoderm pedicellariae. Bioinspiration \& biomimetics, 7(4), 044001.

Lozano, J.; Galera, J.; López, S.; Turon, X. \& Palacin, C. (1995). Biological cycles and recruitment of Paracentrotus lividus (Echinodermata: Echinoidea) in two contrasting habitats. Marine Ecology Progress Series, 122, 179-191. 
Magna, R. L.; Gabler, M.; Reichert, S.; Schwinn, T.; Waimer, F.; Menges, A. \& Knippers, J. (2013). From nature to fabrication: biomimetic design principles for the production of complex spatial structures. International Journal of Space Structures, 28(1), 27-39.

Mancosu, A. \& Nebelsick, J. H. (2020). Tracking biases in the regular echinoid fossil record: The case of Paracentrotus lividus in recent and fossil shallow-water, high-energy environments. PALAEONTOLOGIA ELECTRONICA, 23(2).

Moureaux, C.; Perez-Huerta, A.; Compère, P.; Zhu, W.; Leloup, T.; Cusack, M. \& Dubois, P. (2010). Structure, composition and mechanical relations to function in sea urchin spine. Journal of Structural Biology, 170(1), 41-49.

Nebelsick, J. H.; Dynowski, J. F.; Grossmann, J. N. \& Tötzke, C. (2015). Echinoderms: hierarchically organized light weight skeletons. In Evolution of lightweight structures (pp. 141-155). Springer, Dordrecht.

Nichols, D. \& Currey, J. D. (1968). The secretion, structure and strength of echinoderm calcite. Cell structure and its interpretation, 251-261.

Oldfield, S. C. (1976). Surface ornamentation of the echinoid test and its ecologic significance. Paleobiology, 2, 122-130.

Perricone, V.; Grun, T.; Marmo, F.; Langella, C. \& Carnevali, M. D. C. (2020). Constructional design of echinoid endoskeleton: main structural components and their potential for biomimetic applications. Bioinspiration \& Biomimetics, 16, 011001.

Philippi, U. \& Nachtigall, W. (1996). Functional morphology of regular echinoid tests (Echinodermata, Echinoida): a finite element study. Zoomorphology, 116(1), 35-50.

Presser, V.; Schultheiß, S.; Berthold, C. \& Nickel, K. G. (2009). Sea urchin spines as a model-system for permeable, light-weight ceramics with graceful failure behavior. Part I. Mechanical behavior of sea urchin spines under compression. Journal of Bionic Engineering, 6(3), 203-213.

Presser, V.; Schultheiß, S.; Kohler, C.; Berthold, C.; Nickel, K. G.; Vohrer, A., ... \& Stegmaier, T. (2011). Lessons from nature for the construction of ceramic cellular materials for superior energy absorption. Advanced engineering materials, 13(11), 1042-1049.

Smith, A. B. (1980a). Stereom microstructure of the echinoid test. Special Papers in Paleontology, 25,1-81.

Smith, A. B. (1980b). The structure and arrangement of echinoid tubercles. Philosophical Transactions of the Royal Society B, 289, 1-54.

Telford, M. (1985). Domes, arches and urchins: the skeletal architecture of echinoids (Echinodermata). Zoomorphology, 105(2), 114-124.

Tsafnat, N.; Gerald, J. D. F.; Le, H. N. \& Stachurski, Z. H. (2012). Micromechanics of sea urchin spines. PloS one, 7(9), e44140.

Vogel, S. (2013). Comparative biomechanics: life's physical world. Princeton University Press.

Wester, T. (2002). Nature teaching structures. International Journal of Space Structures, 17, 135-147.

Wester, T. (1984). Structural order in space: the plate-lattice dualism. Plate Laboratory, Royal Academy of Arts, School of Architecture.

Wester, T. (1990). A geodesic dome-type based on pure plate action. International Journal of Space Structures, 5, 155-167. 
Wilkie, I. C. (2005) Mutable collagenous tissue: overview and biotechnological perspective. Progress in Molecular and Subcellular Biology, 39, 221-250

Resumen: Los equinoides, conocidos como erizos de mar, son invertebrados que pueblan los mares desde finales del Ordovícico. Durante su evolución, se sometieron a una radiación adaptativa relevante que condujo a una variedad de formas y estilos de vida especializados. La mayor parte del éxito evolutivo de los equinoides se debe sin duda al empleo estratégico de su endoesqueleto, con especial referencia a la estructura coherente de la capa de la prueba adaptada para resistir las tensiones bióticas y abióticas relacionadas con los entornos marinos. Esta estructura optimizada, que minimiza tanto la energía como los materiales empleados, también podría representar un modelo ideal para transferir soluciones funcionales bioinspiradas a construcciones de edificios y diferentes sectores industriales. La presente contribución pretende proporcionar una breve descripción de la adaptación morfofuncional estratégica equinoide de la prueba y su potencial en el campo biomimético.

Palabras clave: Equinoides - Endoesqueleto - Ensayo - Diseño mecánico - Estructuras de concha - Morfología funcional - Biomimética

Resumo: Equinóides, conhecidos como ouriços-do-mar, são invertebrados que povoam os mares desde o final do Ordoviciano. Durante sua evolução, eles sofreram uma radiação adaptativa relevante levando a uma variedade de formas e estilos de vida especializados. A maior parte do sucesso evolutivo dos equinoides é certamente devido ao emprego estratégico de seu endoesqueleto, com particular referência à estrutura de concha coerente do teste adaptada para resistir a estresses bióticos e abióticos relacionados a ambientes marinhos. Esta estrutura otimizada, que minimiza a energia e os materiais empregados, também pode representar um modelo ideal para a transferência de soluções funcionais bioinspiradas para construções de edifícios e diferentes setores industriais. A presente contribuição pretende fornecer uma breve visão geral sobre a adaptação morfofuncional estratégica equinoide do teste e seu potencial no campo biomimético.

Palavras chave: Equinóides - Eoesqueleto - Teste - Projeto mecânico - Estruturas de casca - Morfologia funcional - Biomimética 